\title{
Política de Cotas e a Educação como Direito Social: Um breve relato sobre a implementação dessa política no Instituto Federal de Educação, Ciência e Tecnologia
}

\section{de Santa Catarina}

Quota Policy and Education as Social Law: A brief report on the implementation of this policy at the Federal Institute of Education, Science and Technology of Santa Catarina

Política de Cotas y la Educación como Derecho Social: Un breve relato sobre la implementación de esa política en el Instituto Federal de Educación, Ciencia y Tecnología de Santa Catarina

Recebido: 18/03/2021 | Revisado: 24/03/2021 | Aceito: 25/03/2021 | Publicado: 03/04/2021

Viviane Aparecida Trindade ORCID: https://orcid.org/0000-0001-8773-5621 Universidade Alto Vale do Rio do Peixe, Brasil E-mail: vivi.ap.trindade03@gmail.com Levi Hülse

ORCID: https://orcid.org/0000-0002-9974-6325 Universidade Alto Vale do Rio do Peixe, Brasil E-mail: levi.hulse@uniarp.edu.br

\begin{abstract}
Resumo
O Ensino Superior brasileiro expandiu-se fortemente nos últimos anos e a adoção de políticas públicas para acesso e permanência do estudante trouxeram, às instituições de ensino superior, um número elevado de estudantes provenientes de escolas públicas e em condições socioeconômicas adversas. Este Artigo é resultado de uma investigação bibliográfica sobre a educação como direito social e o marco histórico de Cotas no Brasil e sua legislação, bem como, a implementação no Instituto Federal de Educação Ciência e Tecnologia de Santa Catarina.

Palavras-chave: Educação; Ações afirmativas; Cotas.
\end{abstract}

\begin{abstract}
Brazilian Higher Education has expanded strongly in recent years and the adoption of public policies for student access and permanence has brought to higher education institutions a high number of students from public schools and in adverse socioeconomic conditions. This Article is the result of a bibliographic investigation on education as a social right and the historical framework of Quotas in Brazil and its legislation, as well as the implementation at the Federal Institute of Education, Science and Technology of Santa Catarina.
\end{abstract}

Keywords: Education; Affirmative actions; Quotas.

\section{Resumen}

La Enseñanza Superior brasileña se expandió fuertemente en los últimos años y la adopción de políticas públicas para acceso y permanencia del estudiante trajeron, a las instituciones de enseñanza superior, un número elevado de estudiantes procedentes de escuelas públicas y en condiciones socioeconómicas adversas. Este artículo es el resultado de una investigación bibliográfica sobre la educación como derecho social y el marco histórico de Cotas en Brasil y su legislación, así como la implementación en el Instituto Federal de ducación, Ciencia y Tecnología de Santa Catarina.

Palabras clave: Educación; Acción afirmativa; Cuotas.

\section{Introdução}

O problema da pesquisa que resultou no presente Artigo é se a implementação da política de Cotas no Instituto Federal de Educação, Ciência e Tecnologia de Santa Catarina (IFSC).

O seu objetivo é trazer um breve relato do marco histórico da Lei de Cotas no Brasil, sua legislação vigente e como foi a implementação no IFSC.

Destarte, neste artigo, parágrafos cruciais são reproduzidos, apresentando o mesmo teor com que foram abordados nos capítulos. Nesse momento, não se indicam referências às fontes consultadas nas Considerações Finais, pois, ao longo de todo o 
desenvolvimento do texto, houve extrema cautela em indicar, devidamente, em nota de rodapé, todas as fontes utilizadas. A sua estrutura capitular é composta pela presente Introdução, seguida dos itens e sub-itens do conteúdo nuclear e das Considerações Finais. Por derradeiro, a Relação das Fontes Citadas.

\section{Metodologia}

A metodologia (métodos e técnicas) utilizada da pesquisa foi: a técnica da pesquisa bibliográfica qualitativa, com análise documental. Esta pesquisa documental, conforme Kripka, Scheller e Bonotto (2015) ela é representada por um ativo e amplo exame de diversos materiais que podem ser revistos, buscando-se assim outras interpretações ou informações que venham a complementar, chamados de documentos.

Para a análise e a interpretação, consoante Bardin (1979) utilizou-se a técnica de análise de conteúdo, que capacita a melhor compreensão do discurso, o aprofundamento de suas características e da coleta dos trechos mais importantes. Que ainda sobre a análise dos dados obtidos durante a pesquisa demandou interpretação, que consistiu em estabelecer a ligação entre os documentos obtidos com outros já conhecidos, advindos de teorias, ou estudos realizados anteriormente.

Aduz Gil (2010) na pesquisa documental, como os dados são conquistados de forma indireta, através de livros, jornais, papéis oficiais, registros estatísticos, fotos, discos, filmes e vídeos, tais fontes evitam desperdício de tempo, oportunizando alcançar a quantidade e qualidade de dados que sejam suficientes para a realização pesquisa.

\section{Educação como Direito Social}

A educação é um direito social estabelecido no artigo $6^{\circ}$, CRFB/88 e tratado de forma específica no Título da Ordem Social nos artigos 205 a 214 da Constituição de 88. A regulação desses artigos da ordem social se dá em específico pela Lei de Diretrizes e Bases da Educação Nacional (LDB), de 1996, e a alteração proposta pela Emenda Constitucional no 59, de 2009, que preservam a educação básica como direito público inerente, contemplando a obrigatoriedade da mesma dos 4 aos 17 anos de idade, onde se explicitam inúmeros aspectos que envolvem a concretização desse direito. Como exemplo, podem-se mencionar os princípios e os objetivos que a instruem, os deveres de cada um dos entes da Federação (União, Estados, Distrito Federal e Municípios) e a garantia desses, à disposição educacional brasileira, também a previsão de um sistema próprio que a financia.

Concernente à LDB/96 (Brasil, 2011), preconiza-se que a educação abarca os processos formativos que se avoluma na vida familiar, na convivência humana, nas relações de trabalho, nas instituições de ensino e pesquisa, nas organizações da sociedade civil, assim como nas marchas culturais.

Assim, à luz das palavras de Peres (2018), enuncia-se que o direito à educação na CRFB/88 como direito de todos, nas Constituições que antecederam a ditadura, havia a defesa do direito de todos à escolaridade, mas a gratuidade era restrita àqueles que evidenciassem carência de recursos.

Necessário comentar, conforme Kelbert (2011), que o maior aporte produzido pela Carta Constitucional de 1988 foi a inserção explícita dos direitos sociais no Título II - Dos direitos e garantias fundamentais, enaltecendo-os, assim, à categoria de direitos fundamentais. Antes, tais direitos se enquadravam apenas como "direitos econômicos e sociais". Assim aduz as EC n 90 (Brasil, 2015) que trouxe a educação sob perspectiva política e de interesse público, inserindo a educação, a alimentação e o transporte como um direito social previsto no artigo $6^{\circ}$.

Porém, com o advento da Constituição da República Federativa do Brasil de 1988, efetiva-se a discussão do preceito acerca da sua caracterização como direitos fundamentais.

Cretella, por sua vez, reitera que todo cidadão brasileiro tem o subjetivo público de exigir do Estado o cumprimento da prestação educacional, independentemente de vaga, sem seleção, porque a regra jurídica constitucional o investiu nesse 
status, colocando o Estado, ao lado da família, no poder-dever de abrir a todos as portas das escolas públicas e, se não houver vagas nestas, das escolas privadas, pagando as bolsas aos estudantes (Cretella apud Raposo, 2005, p. 4).

Alude Silva (apud Camara, 2013) que a educação, como direito social, ordena ao Estado exercer sua função com mais potência, “[...] os direitos sociais, como compreensão dos direitos fundamentais do homem, são prestações positivas estatais, enunciadas em normas constitucionais, que possibilitam melhores condições de vida aos mais fracos, direitos que tendem a realizar a igualização de situações sociais desiguais." (Silva apud Camara, 2013, p. 258)

Consoante Camara (2013), a conquista da educação como direito social é de todos os partícipes, sendo a ligação entre a efetivação dos direitos para a diligência de uma cidadania política, isto é, uma condição fundamental ao pleno desenvolvimento da personalidade humana, enquadrando-se no rol dos direitos e garantia individuais.

\section{Histórico de Cotas no Brasil}

É explícito, no artigo $205^{1}$ da Constituição da República Federativa do Brasil, de 05 de outubro de 1988 (CRFB/88)², que a educação é um direito de todos e é encarada atualmente como um instrumento de luta para a defesa dos direitos sociais por grupos historicamente excluídos e marginalizados. A educação é um dos direitos sociais esculpidos no artigo $6^{\circ}$ da $\mathrm{CRFB} / 88^{3}$. Antes de ser um direito social, apresenta-se como um Direito Humano, reconhecido no art. 26 da Declaração Universal dos Direitos Humanos de $1948^{4}$ (DUDH), que foi um marco na história:

1.Todo ser humano tem direito à instrução. A instrução será gratuita, pelo menos nos graus elementares e fundamentais. A instrução elementar será obrigatória. A instrução técnico-profissional será acessível a todos, bem como a instrução superior, esta, baseada no mérito. 2. A instrução será orientada no sentido do pleno desenvolvimento da personalidade humana e do fortalecimento do respeito pelos direitos humanos e pelas liberdades fundamentais. A instrução promoverá a compreensão, a tolerância e a amizade entre todas as nações e grupos raciais ou religiosos, e coadjuvará as atividades das Nações Unidas em prol da manutenção da paz. 3. Os pais têm prioridade de direito na escolha do gênero de instrução que será ministrada a seus filhos. (UNICEF, 2008, p.14)

Assim, falar de educação como um direito humano seria além de mencionar apenas condições econômicas ou sociais, culturais, étnicas e raciais dos estudantes, mas vislumbrar que todas as pessoas possam exercer seus direitos e ser cientes deles. Portanto, "[...] a educação se configura não apenas como um direito humano e fundamental que permite o ser humano desenvolver e ampliar as capacidades para viver e se relacionar no mundo, mas como uma estratégia de luta política”. (Souza, 2016, p. 140)

As mudanças no ensino superior brasileiro apresentaram grandes avanços, ocorrendo uma expansão significativa do número de matrículas com um crescimento acumulado entre o ano de 2007, momento esse em que o número de 15,4\% de ingressantes saltou para 33\% no ano de 2017. (Brasil, 2018).

Entender o que são e para que servem as cotas é fundamental. Compreende-se por cotas um exemplo de política de ações afirmativas, com o objetivo de garantir menores desigualdades socioeconômicas e educacionais aos membros pertencentes a uma sociedade. Essas ações afirmativas podem existir em diversos meios, mas a sua obrigatoriedade é mais

\footnotetext{
1 “Art. 205. A educação, direito de todos e dever do Estado e da família, será promovida e incentivada com a colaboração da sociedade, visando ao pleno desenvolvimento da pessoa, seu preparo para o exercício da cidadania e sua qualificação para o trabalho". (BRASIL, 1988, p.154)

${ }^{2}$ De acordo com Silva (2021), a Constituição de 1988 foi elaborada durante os trabalhos da Assembleia Constituinte de 1987 e é considerada o marco que deu início ao período democrático conhecido como Nova República. Essa Constituição foi resultado de 20 meses de trabalho. Durante esse tempo, os constituintes debateram exaustivamente os termos que compõem a Constituição Cidadã, chamada assim.

3 “Art. $6^{\circ}$ São direitos sociais a educação, a saúde, a alimentação, o trabalho, a moradia, o transporte, o lazer, a segurança, a previdência social, a proteção à maternidade e à infância, a assistência aos desamparados, na forma desta Constituição”. (BRASIL, 1988, p. 12)

${ }^{4}$ A Declaração Universal dos Direitos Humanos (DUDH) é um documento marco na história dos direitos humanos. Elaborada por repre sentantes de diferentes origens jurídicas e culturais de todas as regiões do mundo, a Declaração foi proclamada pela Assembleia Geral das Nações Unidas em Paris, em 10 de dezembro de 1948, por meio da Resolução 217 A (III) da Assembleia Geral como uma norma comum a ser alcançada por todos os povos e nações. Ela estabelece, pela primeira vez, a proteção universal dos direitos humanos. (UNICEF, 2008)
} 
notada no setor público, como no ingresso nas universidades, concursos públicos e bancos. Assim, as ações afirmativas podem ser compreendidas como ações compensatórias e que buscam a correção de uma situação de discriminação e de desigualdade em que se encontram determinados grupos sociais.

Importa mencionar que Bergmann (1996 apud Souza, 2020) define como ação afirmativa o ato de planejamento e atuação; em sentido amplo a promoção da representação de alguns tipos de classes de pessoas, ou seja, as pertencentes dos grupos excluídos. Silva (2003, p. 20-21) explica que "a ação afirmativa é uma iniciativa essencial de promoção da igualdade, [cujo principal objetivo] para as pessoas negras é combater o racismo e seus efeitos duradouros de ordem psicológica, além de introduzir mudanças de ordem cultural e de convivência entre os chamados diferentes”.

Inicialmente, o sistema de cotas foi criado nos Estados Unidos, com exatidão em 1960, com o intuito de dirimir e de atenuar as desigualdades sociais e econômicas entre negros e brancos. Hoje, a reserva de vagas é considerada facultada pelas universidades na seleção de seus estudantes. Como não há, já que neste país não é realizado o vestibular no formato tradicional como se conhece, algumas instituições priorizam aspectos socioeconômicos para selecionar alguns estudantes e critérios qualitativos.

Tenciona-se que as cotas sociais são um método de facilitar o acesso à educação para pessoas pertencentes a classes desfavorecidas, minoria. Vale ressaltar que, ao falar sobre uma minoria, não se refere essencialmente a um conjunto de pessoas em menor número na sociedade, mas acerca de um grupo em desvantagem social quando confrontado a outros com maiores vantagens, encaixando assim as mulheres, negros LGBTs (Lésbicas, gays, bissexuais e transexuais). Conforme Silveira (2019), "essa parcela da sociedade é considerada, pois está em estado de vulnerabilidade social ${ }^{5}$, ou seja, não tem acesso a alguns direitos, o que os coloca em desvantagem".

As dificuldades do acesso à educação superior no Brasil representam uma adversidade histórica e se acirram ainda mais quando se referem às universidades públicas federais, onde há maiores manifestações das desigualdades educacionais, pois ocorre a prevalência da lógica da privatização do ensino. Em relação ao marco legislativo da Lei de Cotas, preconiza-se, inicialmente, lembrar da Convenção Internacional sobre Eliminação de todas as Formas de Discriminação Racial da Organização das Nações Unidas, explícito no Decreto $n^{\circ}$ 65.810, de, 8 de dezembro de 1969, em que o Estado brasileiro se compromete a adotar as ações afirmativas como uma espécie de promoção da igualdade para incluir grupos que, historicamente, foram deixados de lado no processo de desenvolvimento.

Elucidado esse ponto, segue-se para um contexto entendível na CRFB/88, que solidificou o princípio da igualdade perante lei, "Art. $5^{\circ}$ Todos são iguais perante a lei, sem distinção de qualquer natureza, garantindo-se aos brasileiros e aos estrangeiros residentes no País a inviolabilidade do direito à vida, à liberdade, à igualdade, à segurança e à propriedade, [...]". (Brasil, 1988, p.3)

Já em meados de 1999, Miranda (2018) aponta o projeto de lei da deputada Nice Leão que encaminhou ao Congresso Nacional (PL no 73/99), o qual tratava sobre o ingresso de estudantes nas universidades federais, prevendo a reserva de 50\% das vagas nas universidades públicas para alunos dos cursos de ensino médio, tendo por base o Coeficiente de Rendimento $(\mathrm{CR})^{6}$.

No ano de 2001, outro marco imperioso acerca do debate sobre políticas de ações afirmativas foi a Conferência Mundial de Durban (Conferência Mundial de Combate ao Racismo, Discriminação Racial, Xenofobia e Intolerância), realizada na África do Sul. Conforme Miranda (2018), nessa conferência, o governo brasileiro rubricou a Declaração de Durban, a qual

\footnotetext{
${ }^{5}$ Conforme Resolução Consup n⿳40 $41 / 2017$, o termo vulnerabilidade social é: "art. $2^{\circ}$ Parágrafo único. Vulnerabilidade Social para os fins de aplicação desta resolução deve ser apreendida como processos de exclusão, discriminação ou enfraquecimento dos grupos sociais e sua capacidade de reação, como situação decorrente da pobreza, privação e/ou fragilização de vínculos afetivorrelacionais e de pertencimento social”. (IFSC, 2018)

${ }^{6}$ Conforme informação no site da UNIFESP (2014), o coeficiente de Rendimento (CR) é o índice que mede, ao longo do curso, o desempenho acadêmico do estudante ao fim de cada período letivo. O valor do CR varia de 0 (zero) a 10 (dez) e se encerra na terceira casa decimal sem arredondamento.
} 
se dispõe a conceber medidas de inclusão e de combate à discriminação racial, sendo decisiva a posição do Brasil para o enriquecimento do debate e para a definição das primeiras tentativas de ações afirmativas no ensino superior. É considerável salientar que, embora alguns teóricos demarquem como resultado dessa conferência a criação de medidas de ações afirmativas, o termo está oculto no documento.

Assevera Ferreira (2019) que o grande marco para a aprovação das cotas raciais em universidades públicas adveio da III Conferência Mundial Contra o Racismo Discriminação Racial, Xenofobia e Intolerância correlata, realizada em Durban, na África do Sul, em meados de setembro de 2001, solicitada pela ONU em 1997, ou seja, “[...] cada país deveria levar propostas concretas para o progresso da equidade racial, a proposta brasileira chamou atenção da mídia, levantando o tema das cotas raciais nas universidades". A partir desse notório momento se concretiza a Política de Ação Afirmativa, que ficaria conhecida como sistema de cotas raciais.

No Brasil, o sistema de cotas tornou-se afamado, inicialmente pela Universidade do Estado do Rio de Janeiro (UERJ), que foi a pioneira no país a implantar um sistema de cotas em vestibulares superiores, e a Universidade Estadual do Norte Fluminense Darcy Ribeiro (UENF), ainda que por meio de uma lei estadual que designava 50\% das vagas do processo seletivo para alunos advindos de escolas públicas. São as Leis Estaduais n $\mathrm{n}^{\circ} 3.524$, de 28 de dezembro de 2000, e $\mathrm{n}^{\circ} 3.708$, de 9 de novembro de 2001, organizadas pelos Decretos Estaduais $n^{\circ}$ 30.766, de 4 de março de 2002, e $n^{\circ} 4.061$, de 2 de janeiro de 2003. Essas, por sua vez, criaram, naquele estado, e pela primeira vez na educação brasileira, o que se conhece hoje como sistema de reserva de vagas no ensino superior por cotas, sendo essas destinadas aos candidatos que pertenciam à população negra e parda, portadores de deficiência física e estudantes que cursaram o ensino médio em escolas públicas, destinando-se o percentual de $40 \%$ das vagas gratuitas da UERJ e da UENF a integrantes dos alusivos grupos. Depois foi a vez da Universidade de Brasília (UnB); essa, no entanto, propôs-se a estipular as ações afirmativas para negros no vestibular de 2004.

Entender a diferença entre cotas sociais e cotas raciais é primordial para a discussão. No Quadro 1, Silveira (2019) apresenta um comparativo para elucidar tal questão:

Quadro 1 - Comparativo entre Cotas Raciais e Cotas Sociais.

\begin{tabular}{|c|c|c|}
\hline & Cotas Raciais & Cotas Sociais \\
\hline Minorias Englobadas & Pretos, Pardos e Indígenas & $\begin{array}{l}\text { Estudantes que cursaram integralmente o } \\
\text { ensino médio em escolas públicas, estudantes } \\
\text { com renda familiar abaixo de } 1,5 \text { salário } \\
\text { mínimo e pessoas com deficiência }(\mathrm{PcD})\end{array}$ \\
\hline Descrição & $\begin{array}{l}\text { São minorias étnicas, } \\
\text { discriminadas por conta de sua } \\
\text { cor de pele e cultura, } \\
\text { amplamente afetadas durante o } \\
\text { período de escravidão no Brasil }\end{array}$ & $\begin{array}{l}\text { Esse tipo de cota é criado, a fim de amparar } \\
\text { estudantes que foram prejudicadas devido à } \\
\text { falta de acesso a uma educação de qualidade } \\
\text { durante o ensino médio cursado em escolas } \\
\text { públicas }\end{array}$ \\
\hline
\end{tabular}

Fonte: Politize (2019).

A distinção entre as cotas sociais e as raciais leva em consideração fatores diversos que não a raça do candidato. No Brasil, as políticas de cotas sociais destinam-se, ainda, a estudantes de escola pública, estudantes de baixa renda familiar e a pessoas com deficiência. A aplicação desse tipo de cota sobrevém, principalmente, no Exame Nacional do Ensino Médio $(\mathrm{ENEM})^{7}$ e no Sistema de Seleção Unificada (SISU) ${ }^{8}$.

\footnotetext{
${ }^{7}$ De acordo com informação no portal MEC (2018) em 1998 criou-se o Exame Nacional do Ensino Médio (Enem), o qual tem o objetivo de avaliar o desempenho do estudante ao fim da escolaridade básica. Podem participar do exame alunos que estão concluindo ou que já concluíram o ensino médio em anos anteriores. O Enem é utilizado como critério de seleção para os estudantes que pretendem concorrer a uma bolsa no Programa Universidade para Todos (ProUni).
} 
Cabe aqui demonstrar que o ENEM foi criado em 1998 pelo Instituto Nacional de Estudos e Pesquisas Educacionais (INEP) com o objetivo de avaliar o desempenho do estudante ao final da educação básica. O exame destina-se aos alunos concluintes e aos egressos do ensino médio. Até 2008, o exame compunha-se por uma prova objetiva com questões interdisciplinares e uma redação. Com a reformulação do exame em 2009, esse passou a ser composto por quatro provas objetivas, subdivididas em quatro áreas do conhecimento, cada uma com 45 questões, e por uma redação com temas diversos ou os mais comentados no ano. No entanto, a partir de 2009, passou a ser utilizado como mecanismo de seleção para as instituições públicas de ensino por meio do SISU.

Quando se menciona a questão das vagas nas universidades públicas, sobre o termo cotas, Trevisol e Nierotka (2015, p. 575) indicam ser uma situação viável e perceptível de justiça social e divisão da pirâmide de riquezas que inclui o poder do

Estado, "[...] o acesso ao ensino superior público e gratuito ter sido até hoje privilégio (com poucas exceções) das classes médias/altas e brancas e que por isso controlam o Estado como um todo".

Presentemente, universidades públicas adotam políticas afirmativas variadas, que, conforme seu regimento, diversificam-se. Porém, assemelham-se ao reservar uma porcentagem das vagas disponíveis na instituição para candidatos que se autodeclararem negros, indígenas ou evidenciarem comprovação de renda abaixo do limite no caso das cotas sociais.

Para Moehlecke (2002, p. 197) "[...] a ideia de ação afirmativa, ou discriminação positiva” vinha com a exigência do Estado da garantia de leis antissegregacionistas e o acordo com melhores condições de vida dos negros no país". Sustentada pelo entendimento de Fraser (2006), a justiça hoje suplica tanto redistribuição quanto aprovação, afiança que as políticas públicas de ação afirmativa se fundam numa versão da política cultural com a da diferença, podendo ser acertadamente combinada com a política social da igualdade, isto é, a política de cotas não é apenas racial, mas socioeconômica.

Sendo assim, é compreendido por política de cotas o modelo de ações afirmativas que intenciona a diminuição das desigualdades socioeconômicas e educacionais entre partícipes de uma sociedade, principalmente o que diz respeito ao ingresso nas Instituições de Ensino Superior (IES), concursos públicos e vestibulares.

Conforme Hulse e Klaus (2020) a inclusão social vem capacitando as pessoas hipossuficientes para que estas tenham oportunidades, assim, as mesmas começam a participar das decisões que afetam suas vidas e ainda conseguem ter acesso aos serviços, espaços políticos, sociais e físicos.

\section{Legislação e Normas Vigentes sobre as Cotas no Brasil}

$\mathrm{Na}$ área regimental, delibera-se como marcos incluindo a diversidade na área da educação, com a Lei $\mathrm{n}^{\circ}$ 10.639/03, que torna obrigatório o ensino de história e cultura afro-brasileira e africana na rede de ensino e as Diretrizes Curriculares Nacionais para a Educação das Relações Étnico-Raciais, Resolução no 1/2004, estabelecidas pelo Conselho Nacional da Educação (CNE).

O Ministério da Educação (MEC), sob direção, à época, do ministro Tarso Genro, originou, no ano de 2004, uma secretaria específica: a chamada Secretaria de Educação Continuada, Alfabetização e Diversidade (SECAD) com a finalidade de vincular, entre outras situações, as ações de inclusão social com a valorização da diversidade étnica e cultural brasileira. Porém, em razão de debates atuais, conforme elucida Souza (2019), ocorre a extinção da referida secretaria por meio do Decreto $\mathrm{n}^{\circ}$ 9.465, de 2 de janeiro de 2019, fato que mostra um retrocesso no campo dos direitos educacionais, ficando explícito como uma medida que vai na direção contrária do reconhecimento da diversidade, da promoção da equidade e do fortalecimento da inclusão no processo educativo.

${ }^{8}$ O Sistema de Seleção Unificada (SISU) foi desenvolvido pelo Ministério da Educação para selecionar os candidatos às vagas das instituições públicas de ensino superior que utilizarão a nota do Exame Nacional do Ensino Médio (ENEM) como única fase de seu processo seletivo. A seleção é feita pelo Sistema com base na nota obtida pelo candidato no Enem. (BRASIL, 2018) 
Em julho de 2010, aprovou-se a Lei $n^{\circ} 12.288$, que dispõe sobre o Estatuto da Igualdade Racial. Esse Estatuto prevê a efetivação da igualdade de oportunidades à população negra e uma das medidas para esse fim foi a adoção dos programas de ações afirmativas por parte do poder público.

Desde então, os debates se intensificaram e algumas experiências se concretizaram após várias discussões e polêmicas acerca do tema até que no ano de 2012, precisamente em abril, o Supremo Tribunal Federal (STF) decidiu pela constitucionalidade da adoção do sistema de Cotas. Em 29 de agosto de 2012, sancionou-se a famosa Lei $\mathrm{n}^{\circ} 12.711$ com o objetivo de reservar 50\% (cinquenta por cento) das matrículas por curso nas universidades e nos institutos federais para estudantes oriundos de escola pública, negros e indígenas. A lei foi aplicada de forma gradual e progressiva.

Em 2013, o primeiro ano, as universidades eram obrigadas a reservar no mínimo 12,5\% (doze e meio por cento) de suas vagas. Estão incluídas, segundo o MEC, 59 universidades federais e 38 institutos federais de educação. A lei também deverá ser revisada após dez anos de sua promulgação.

O Plano Nacional de Educação9 (PNE) para o decênio 2015-2024, conforme Lei No 13.005/14, estabeleceu em uma das suas vinte metas, que:

Meta 12: elevar a taxa bruta de matrícula na educação superior para 50\% (cinquenta por cento) e a taxa líquida para $33 \%$ (trinta e três por cento) da população de 18 (dezoito) a 24 (vinte e quatro) anos, assegurada a qualidade da oferta e expansão para, pelo menos, $40 \%$ (quarenta por cento) das novas matrículas, no segmento público (BRASIL, 2014).

Os debates acalorados em relação ao tema cercavam, especialmente, as esferas mais conservadoras da sociedade, a mídia dominante, os estudiosos e líderes de movimentos sociais. Souza (2015) relembra que, enquanto alguns notoriamente eram contrários a essa mudança significativa, outros muitos tentavam expor dados estatísticos em relação à necessidade de reparação histórica e de justiça social. Sendo assim, os critérios socioeconômicos e étnico-raciais foram fundamentais para a adoção de reserva de vagas.

Destaca-se também a Lei $n^{\circ} 13.409$, de 28 de dezembro de 2016. Essa, por sua vez, altera a Lei $n^{\circ} 12.711$, de 29 de agosto de 2012 a fim de dispor sobre a reserva de vagas para pessoas com deficiência nos cursos técnico de nível médio e superior das instituições federais de ensino.

A referida Lei de Cotas instituiu um marco para a educação superior pública brasileira e, a partir de sua aprovação, passou a exigir que os institutos técnicos federais e as universidades públicas federais reservassem no quadro de suas vagas $50 \%$ (cinquenta por cento) para estudantes que cursaram integralmente na rede pública o ensino médio para o acesso às universidades federais e o ensino Fundamental para o ingresso aos Institutos Federais.

Demonstra-se, na Figura 1, como funciona o cálculo para a reserva de vagas da referida lei. 
Figura 1 - Demonstrativo para reserva de Vagas no IFSC.

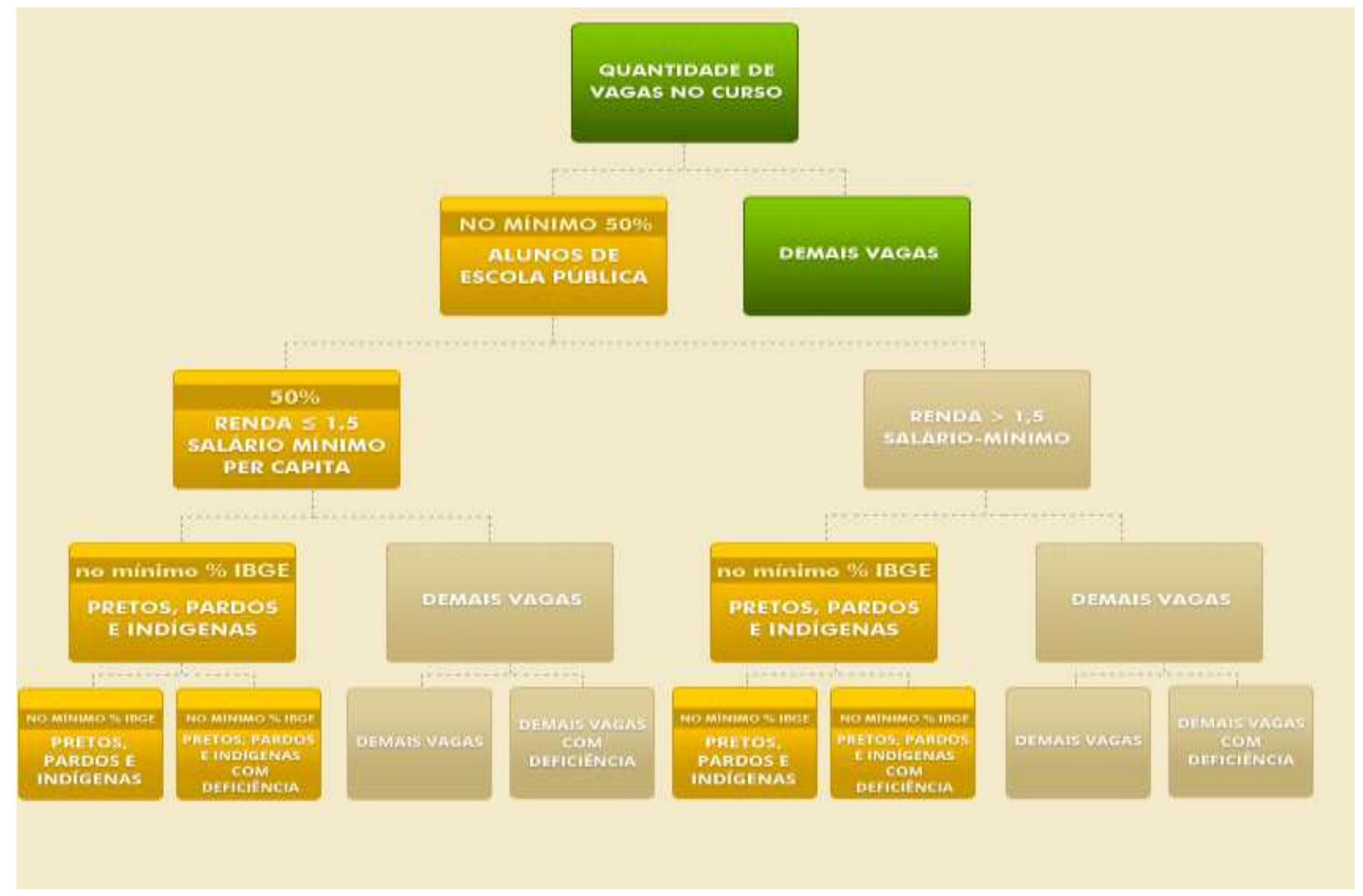

Fonte: MEC (2012).

Conforme Figura 1, o alusivo sistema de cotas para escolas públicas vale para todos os tipos de curso técnicos (Proeja, integrado, concomitante e subsequente) e também de graduação (bacharelado, licenciatura e superior de tecnologia). Para os candidatos aos cursos técnicos, esses devem ter feito todo o ensino fundamental (da $1^{\mathrm{a}}$ a $8^{\mathrm{a}}$ série ou $9^{\mathrm{o}}$ ano, dependendo do caso) em instituição pública (federal, estadual ou municipal). Já para quem quer concorrer a vagas na graduação por meio do sistema de cotas, a exigência é ter estudado todo o ensino médio em escolas públicas.

Também, engloba-se quem fez educação de jovens e adultos (EJA) ou tem certificado de conclusão do ensino médio com base no resultado do ENEM no Exame Nacional para Certificação de Competências de Jovens e Adultos (Encceja) ou, ainda, em exames de certificação realizados por sistemas estaduais de ensino.

Já a respeito da divisão das vagas em cada curso, metade dessas vão para o Sistema de Cotas e metade fica para ampla concorrência. Na chamada ampla concorrência, participam todos os candidatos, incluindo os que optaram pelas cotas. Sendo assim, depois de preenchidas as vagas da ampla concorrência, o candidato que optou pelas cotas e não foi aprovado para o curso nesse primeiro momento concorre às vagas reservadas para escolas públicas.

Dentro das vagas reservadas para escolas públicas, há duas subdivisões que se necessita entender: cinquenta por cento delas são para quem tem renda familiar bruta igual ou menor que um salário mínimo e meio por pessoa e 50\% para quem tem renda familiar bruta acima desse valor. E, em cada subdivisão dessa, há ainda a reserva aproximada de $16 \%$ das vagas para candidatos autodeclarados pretos, pardos ou indígenas. Esse percentual definiu-se definido com base na proporção de habitantes de Santa Catarina que pertencem a essas raças de acordo com o Instituto Brasileiro de Geografia e Estatística (IBGE). Os $84 \%$ restantes ficam para candidatos que se autodeclaram de outras etnias ou mesmo pretos, pardos e indígenas que não querem concorrer pela reserva de vagas étnico-raciais (IFSC,2013). 
Conforme aduz o resumo técnico do Censo da Educação Superior de 2013 (INEP, 2013), "a evolução no número de matrículas nos cursos de graduação no período de 2010 a 2013, segundo a organização acadêmica da IES. De acordo com o Censo, as matrículas de graduação atingiram o total de 7.305.977 no ano de 2013”. Já o crescimento de ingressantes nos cursos de graduação entre os anos de 2009 e 2019 na rede pública aumentou 32,4\%. Dentro da categoria pública (municipal, estadual e federal), de acordo com dados Inep (2019) a rede federal foi a que mais cresceu em número de matrículas, ou melhor, um montante de $59,1 \%$.

A alusiva Lei das Cotas prediz avaliações constantes num período de dez anos. As discussões e as contendas continuarão sobretudo no que diz respeito à sua aplicação, eficácia e eficiência. Destaca-se que se encaminha uma mudança no perfil dos estudantes das universidades públicas brasileiras e essa deriva com a expectativa da proporcionalidade dessas iniciativas em todo o país.

\section{Implementação de Cotas pelo Instituto Federal de Santa Catarina - IFSC}

O Instituto Federal de Educação, Ciência e Tecnologia de Santa Catarina (IFSC), denominado, até o ano de 2008, como Centro Federal de Educação Tecnológica (CEFET-SC), a antiga Escola Técnica Federal de Santa Catarina (ETF-SC), é uma instituição de ensino, pública e gratuita. Possui a oferta de cursos profissionalizantes diversificados e com níveis diversos de qualificação, ou melhor, cursos de nível médio integrado ao profissionalizante, cursos de nível médio subsequentes destinados a alunos que já concluíram o ensino médio e desejam se qualificar, Formação Inicial e Continuada (FIC), Educação Profissional para Jovens e Adultos (PROEJA), cursos superiores de tecnologia e licenciatura e cursos de pós-graduação lato e stricto sensu.

As primeiras discussões sobre cotas na instituição se deram a partir de 2006 durante a realização do segundo Seminário sobre Ingresso, onde apresentou-se dados referentes ao perfil socioeconômico e étnico-racial dos candidatos inscritos no Exame de Classificação e no Vestibular do ano de 2007.

Nas discussões ocorridas durante o seminário, sentiu-se a necessidade de se constituir um "Grupo de Trabalho para encaminhar ações a serem implantadas nos processos de ingresso, voltadas às diferenças étnico-raciais e socioeconômicas" (IFSC, 2009a, p. 7).

Consoante Ávila (2012), com a criação de um Grupo de Trabalho Ações Afirmativas, mostrou-se a finalidade de construir fundamentos teóricos sobre o tema e encaminhar a discussão à comunidade acadêmica. $\mathrm{O}$ objetivo do grupo era regularizar um Programa de Ações Afirmativas para assim, ampliar o acesso no CEFET-SC. As cotas raciais e sociais nas instituições federais de ensino foram implantadas no IFSC no ano de 2009 e estabelecidas por lei em 2012.

A partir do ingresso do segundo semestre letivo de 2007, o candidato realizou a inscrição totalmente pela internet e o questionário socioeconômico preenchido no ato no próprio programa de inscrição, função essa que facilitou o acesso das informações e a sua extração para análises mais aprofundadas.

O Grupo de Trabalho (GT) pautou-se nas experiências de implementação de reserva de vaga das Universidade Federal de Santa Catarina (UFSC) e Universidade Federal do Paraná (UFPR).

Nos Institutos Federais, conforme demonstrado no Plano de Desenvolvimento Institucional (PDI 2020-2024), prioriza-se a atuação em favor do desenvolvimento local e regional no cenário da construção da cidadania. Em sua intervenção, faz-se necessário explorar as potencialidades de desenvolvimento, a vocação produtiva local, a geração e transposição de tecnologias e conhecimentos e a adição, da mão de obra qualificada.

A estrutura dos Institutos permitiu a formulação de propostas de inclusão social que viessem a favorecer a melhoria das condições de vida de grupos em desvantagem social e que reconhecessem, na diversidade, uma forma diferenciada de 
contribuir para o exercício do direito à educação de qualidade para todos os segmentos da sociedade excluídos dos processos de formação profissional.

As diretrizes políticas de inclusão do CEFET - SC teve aprovação em meados de dezembro de 2008. Aduz Stroisch (2012) que essas medidas foram resumidas em aplicação das ações afirmativas de acesso; utilização dos resultados do ENEM; utilização de procedimentos e recurso de acesso aos cursos PROEJA e de FIC e elaboração do Plano de Inclusão da Instituição, a fim de articular ações inclusivas.

Destaca-se, aqui, de acordo com Vilela (et.al., 2017), que, após a reformulação das políticas de inclusão, a qual incluiu o uso do exame do ENEM, positivamente ocorreu a ampliação das possibilidades de ingresso nas instituições de ensino superior com o referido resultado, visto que o exame se realiza em todas as unidades federativas do país. A contenda promovida pela aprovação da Lei de Cotas, em 2012, teve impactos nos incentivos dos indivíduos contemplados pela política.

O documento intitulado "Políticas de Inclusão da Rede Federal de Ensino Tecnológico", publicado pela SETEC (BRASIL, 2008b, p. 12), define grupos em desvantagem social como sendo "todos aqueles que, por diferentes razões (sociais, econômicas, étnico-raciais ou culturais) apresentam dificuldades de acesso, de permanência ou conclusão no seu percurso formativo em instituições de ensino de qualidade". O certame põe em evidência que tais grupos são reconhecidos em função da sociedade característica como agentes econômicos, políticos e culturais.

Lado a lado às atividades do Grupo de Trabalho Ações Afirmativas, em meados de agosto de 2006, lançou-se o Grupo de Trabalho Permanência e Êxito, que o fez por meio da Portaria nº 291/2006. Tal fato se deu em razão do índice expressivo de evasão identificado em pesquisa realizada na instituição nos anos 2003, 2004 e 2005.

A Lei 11.892/2008 criou a Rede Federal de Educação Profissional, Científica e Tecnológica formada por 38 Institutos Federais de Educação, Ciência e Tecnologia. Assim, o CEFET-SC transformou-se em Instituto Federal de Educação, Ciência e Tecnologia de Santa Catarina.

Com o Decreto $\mathrm{n}^{\circ} 7.824 / 2012$, o qual define as condições gerais de reservas de vagas, estabelece-se a sistemática de acompanhamento das reservas de vagas e a regra de transição para as instituições federais de educação superior.

Já a Portaria Normativa nº 18/2012, do MEC que estabelece os conceitos básicos para aplicação referida lei, esclarece as modalidades das reservas de vagas e as medidas para cálculo, fixa as condições para concorrer às vagas reservadas e determina o fluxo de preenchimento das vagas reservadas. A implantação das cotas funcionará de forma gradual ao longo dos próximos quatro anos, ou seja, até o ano de 2016 todas as instituições deverão alterar seus planos de ingresso, até chegar à metade da oferta total do ensino público superior federal.

No ano seguinte, o Presidente da República alterou a Lei de Cotas para dispor de reserva de vagas aos portadores de deficiência nos cursos técnico de nível médio e superior das instituições federias de ensino, sancionando a Lei no 13.409, de 28 de dezembro de 2016.

Como prediz Bonassa (2010, p. 88), desenvolvem-se ações de inclusão anteriormente à Lei de Cotas na instituição, limitadas, ou melhor, ainda intitulada como Escola Técnica. "[...]Agora como Instituto Federal, as ações de inclusão tomam corpo e tem maior estímulo do governo federal para que se transformem em política institucional".

Alusivo ao PDI (IFSC, 2020a, p. 66), a proposta dessa lei vem ao encontro da a prerrogativa inclusiva já adotada nos processos da instituição, assim:

A noção de igualdade de concorrência ignora os processos de exclusão que ocorrem na sociedade brasileira e a restrição existente para parte da população ao acesso à educação de qualidade. Garantir acesso diferenciado a esses públicos tem sido foco de ações institucionais para todos os níveis e modalidades de ensino. 
Explicitamente, a temática inclusão sobrevém em três textos importantes que norteiam as práticas institucionais, sendo eles: o Plano Pedagógico Institucional (PPI) ${ }^{10}$, elaborado a cada 5 anos; Plano de Desenvolvimento Institucional (PDI) ${ }^{11}$, revisto a cada 4 anos; e o Plano de Inclusão.

No ano de 2007, conforme evoca Bonassa (2010), vem à tona a discussão da reserva de vagas, resultando na criação de critérios e de diretrizes para a política de acesso aos cursos de graduação: reserva de 10\% das vagas dos cursos superiores para negros que, preferencialmente, tenham cursado integralmente o ensino médio em instituições públicas de ensino; reserva de 50\% de vagas para oriundos de escola pública que tenham cursado todo o ensino médio em instituições públicas de ensino.

[...] aponta-se para a institucionalização de uma Política de Inclusão do IFSC, cuja pretensão é desenvolver um conjunto de ações que promovam a preparação para o acesso, o ingresso, a permanência e êxito no percurso formativo na instituição e o acompanhamento da inserção sócio-profissional (sic) dos estudantes egressos. Essas ações, segundo Plano de Inclusão, inserem- se no Programa de Ações Afirmativas, documento anexo ao referido Plano. (Bonassa, 2010, p.95)

No referido Plano de Inclusão, indicam-se quatro fundamentais políticas institucionais que, posteriormente, desenrolam-se em 36 ações. Essas políticas vão desde a democratização do acesso, a permanência e o êxito no itinerário do curso, a inserção no mercado de trabalho do egresso e o reconhecimento e a convivência com as diferenças.

Já as 36 ações, assevera Bonassa (2017), dividem-se na implementação de Decretos, Leis para garantir as políticas aos grupos em desvantagem social, desenvolvimento de formação de docentes, implementação e programas à comunidade escolar, viabilização de aproximação da comunidade externa entre os câmpus, implementação da reserva de vagas nos cursos superiores e técnicos, criação de meios diferentes para o ingresso da comunidade escolar vulnerável, melhoraria das estratégias de divulgação, fortalecendo a identidade da instituição, promover e estimular a permanência e êxito, efetivação da política de assistência estudantil, criação de setores específicos para acompanhar ações de egresso, ampliação dos espaços dos câmpus, adequando às necessidades do estudante, entre outras ações relativas à inclusão efetiva do estudante na instituição.

Atualmente, no Brasil, existem três tipos de cotas: sociais, raciais e por deficiência física. No ato da inscrição, o candidato autodeclara a renda e a origem escolar, mas caso seja aprovado dentro da reserva de vagas é necessário comprovar as informações prestadas. As cotas sociais são as destinadas a pessoas de baixa renda e que tenham formação em escola pública. Analisam-se inúmeros fatores socioeconômicos do candidato. Correntemente, leva-se em consideração os critérios de renda do Cadastro Único para Programas Sociais do Governo Federal (CadÚnico), o qual considera família de baixa renda, que possua renda familiar mensal de até meio salário mínimo por pessoa, ou total de três salários mínimos da renda mensal total. Assevera Silveira (2019) que esse tipo de reserva de vagas sempre está ligado ao requisito de ter estudado todo o ensino médio em escolas públicas. Os estudantes que se enquadram nessa condição ainda têm o direito à isenção na taxa de inscrição dos vestibulares, de acordo com a Lei 12.799 de $2013^{12}$.

As raciais voltam-se a pessoas negras, pardas ou indígenas, que historicamente fazem parte de um grupo que foi oprimido na época da colonização e até hoje sentem os reflexos disso. Conforme Silveira (2018), a eliminação das desigualdades injustas e das vantagens injustas procura estabelecer a igualdade equitativa de oportunidades, pois todos merecem igualdade de consideração. Candidatos nos cursos de graduação do IFSC que se inscrevam para as cotas destinadas a

\footnotetext{
${ }^{10} \mathrm{O}$ Projeto Pedagógico Institucional (PPI) apresenta concepções, princípios e diretrizes que constituem balizas para a atuação do IFSC, indicando os valores, as intenções, as ações e as prioridades da Instituição. Esse projeto, portanto, iluminará as respostas que o IFSC construirá para atender às demandas socioeducacionais com vistas a contribuir com o desenvolvimento humano, social, cultural e econômico nos contextos em que atua. (IFSC, 2009b)

${ }^{11}$ O Plano de Desenvolvimento Institucional (PDI) é o documento destinado a apresentar as estratégias que serão adotadas pela instituição nos próximos cinco anos, visando ao alcance de objetivos e de metas e conferindo identidade e intenções comuns a todos. (IFSC, 2020)

12 Dispõe sobre a isenção de pagamento de taxas para inscrição em processos seletivos de ingresso nos cursos das instituições federais de educação superior.(Brasil, 2013b)
} 
pessoas pretas, pardas ou indígenas devem, no momento da matrícula, entregar a autodeclaração de preto, parda ou indígena e participar da banca de heteroidentificação conforme estabelecido pela Instrução Normativa 16/202013. O procedimento de heteroidentificação é a identificação, por uma comissão destinada pelo IFSC, da condição autodeclarada pelo candidato.

As cotas por deficiência física garantem uma porcentagem das vagas de trabalho em empresas com determinada quantidade de funcionários, garantindo a inclusão de portadores de necessidades especiais no mercado de trabalho. Na IES, as pessoas com deficiência regram-se de acordo com a Lei ${ }^{\circ} 13.409 / 2016^{14}$, a qual contempla a reserva de vagas. Sendo assim, altera os Art. $1^{\circ}$ e $3^{\circ}$ da Lei de Cotas, faz saber:

Art. $1^{\circ}$ Os arts. $3^{\circ}, 5^{\circ}$ e $7^{\circ}$ da Lei $n^{\circ} 12.711$, de 29 de agosto de 2012, passam a vigorar com as seguintes alterações: Art. $3^{\circ} \mathrm{Em}$ cada instituição federal de ensino superior, as vagas de que trata $\mathrm{o}$ art. $1^{\circ}$ desta Lei serão preenchidas, por curso e turno, por autodeclarados pretos, pardos e indígenas e por pessoas com deficiência, nos termos da legislação, em proporção ao total de vagas no mínimo igual à proporção respectiva de pretos, pardos, indígenas e pessoas com deficiência na população da unidade da Federação onde está instalada a instituição, segundo o último censo da Fundação Instituto Brasileiro de Geografia e Estatística - IBGE. (BRASIL, 2016)

Presentemente, no Decreto ${ }^{\circ} 5.296$ de 2 de dezembro de $2004^{15}$, tem-se a distinção referente às pessoas portadoras de deficiência, ou seja, as que possuem alguma limitação ou incapacidade para desempenhar atividades. As deficiências se enquadram em uma destas quatro categorias: deficiência física, deficiência auditiva, deficiência visual, deficiência mental, e deficiência múltipla.

O IFSC indica, em edital de seleção indicando, os documentos necessários para comprovação de renda, deficiência ou para a autodeclaração. Caso o candidato não comprove conforme a documentação necessária escrita em edital, a matrícula é invalidada.

Sendo assim, torna-se fundamental reconhecer-se a importância das políticas públicas de incentivo à educação superior no Brasil, que sensibiliza em favor dos grupos sociais com histórico de exclusão, uma vez que possibilitam entrar na universidade uma cota considerável de diversos grupos sociais, econômicos e étnicos.

\section{Conclusão}

Conforme os resultados da Pesquisa cujo relato hora encerramos, o texto teve como propósito situar os principais marcos legais que definiram as políticas educacionais de ensino superior brasileiro, contextualizando a adoção de ações afirmativas como uma das formas para a democratização do acesso e a permanência dos jovens brasileiros no ensino superior.

Registra-se que a discussão referente as cotas vêm desde 1969, em que o Estado brasileiro se compromete a adotar medidas de ações afirmativas como uma espécie de promoção da igualdade para incluir grupos que, historicamente, foram deixados de lado no processo de desenvolvimento, indicando-se, assim, a necessidade de estudo mais aprofundado para verificação dos motivos que levam o aluno de escola pública de classe vulnerável não optar pela entrada de cotas sociais na graduação ou evadir-se.

A alusiva Lei das Cotas prediz avaliações constantes num período de dez anos. As discussões e as contendas continuarão sobretudo no que diz respeito à sua aplicação, eficácia e eficiência. Destaca-se que se encaminha uma mudança no

\footnotetext{
${ }^{13}$ Regulamenta procedimentos complementares à autodeclaração dos candidatos pretos, pardos e indígenas nos cursos técnicos de nível médio, de graduação e de pós-graduação do Instituto Federal de Santa Catarina. (IFSC, 2020b)

${ }^{14}$ Alteração da Lei no 12.711 , de 29 de agosto de 2012, para dispor sobre a reserva de vagas para pessoas com deficiência nos cu rsos técnico de nível médio e superior das instituições federais de ensino. (Brasil, 2016)

${ }^{15}$ Regulamenta as Leis nos 10.048 , de 8 de novembro de 2000, que dá prioridade de atendimento às pessoas que especifica, e 10.098 , de 19 de dezembro de 2000, que estabelece normas gerais e critérios básicos à promoção da acessibilidade das pessoas portadoras de deficiência ou com mobilidade reduzida, e dá outras providências. (Brasil, 2004)
} 
perfil dos estudantes das universidades públicas brasileiras e essa deriva com a expectativa da proporcionalidade dessas iniciativas em todo o país.

Faz-se saber que o IFSC é uma instituição possuidora de uma estrutura física e profissional invejável, de qualidade e com condições de colocar em prática as diretrizes educacionais e concepções, bem como suas políticas de inclusão, contando com os profissionais agentes do processo e do comprometimento institucional. O IFSC tem tido boa participação no meio social onde está inserido, seja na propagação do ensino, como também nos diversos eventos culturais, e até mesmo filantrópicos, ao longo de seu surgimento.

Demonstrou-se que, em um dos grandes desafios das instituições de ensino superior gerir, de maneira estratégica e tática, o conhecimento criado pela humanidade ao longo de sua história. Com a expansão da Rede Federal representou-se a democratização do acesso à educação, aumentando o número de vagas e promovendo a inclusão de uma parcela importante da sociedade. Frente a isso, surgiram inúmeros desafios, um deles é a promoção, a melhoria do ensino e a manutenção da excelência.

Registra-se que a discussão referente as cotas vêm desde 1969, em que o Estado brasileiro se compromete a adotar medidas de ações afirmativas como uma espécie de promoção da igualdade, a fim de incluir grupos que, historicamente, foram deixados para trás no processo de desenvolvimento. Faz necessário predizer que, a fim de suprimir os desafios encontrados em relação a aplicabilidade da Lei de Cotas no Instituto Federal de Educação, Ciência e Tecnologia de Santa Catarina indica a necessidade de estudo mais aprofundado com dados em relação ao ingressantes na instituição através dessa política afirmativa, tais como ingresso, permanência e êxito dos cotistas.

\section{Referências}

Ávila, H. (2006). Teoria dos Princípios: da definição à aplicação dos princípios jurídicos. (6a ed.), Malheiros Editores.

Bardin, L. (1979). Análise de conteúdo. Edições 70.

Belettati, V. C. F. (2011). Dificuldades de alunos ingressantes na universidade pública: indicadores para reflexões sobre a docência universitária, Tese, orientador: Maria Isabel de Almeida, Faculdade de Educação, Universidade de São Paulo.

Bonassa,G. (2010).A política de inclusão no Instituto Federal de Educação, Ciência e Tecnologia de Santa Catarina: uma proposta de avaliação. Tese. https://repositorio.ufsc.br/handle/123456789/93649

Brasil. (1965). Lei $n^{\circ} 4.759$, de 20 de agosto de 1965. Dispõe sobre a denominação e qualificação das Universidades e Escolas Técnicas Federais. http://www.planalto.gov.br/ccivil_03/Leis/1950-1969/L4759.htm\#: :text=LEI\%20No\%204.759\%2C\%20DE,Art

Brasil. (1969). Decreto n ${ }^{\circ}$ 65.810, de 8 de dezembro de 1969. Promulga a Convenção Internacional sobre a Eliminação de todas as Formas de Discriminação Racial. http://www.planalto.gov.br/ccivil_03/decreto/1950-1969/D65810.html

Brasil. (1988). Constituição da República Federativa do Brasil de 1988. http://www.planalto.gov.br/ccivil_03/constituicao/constituicao.htm

Brasil. (1990). Decreto no 99.710, de 21 de novembro de 1990.Promulga a Convenção sobre os direitos da Criança. http://www.planalto.gov.br/ccivil_03/decreto/1990-1994/D99710.htm>

Brasil. (1994). Lei n ${ }^{\circ} 8.948$, de 8 de dezembro de 1994. Dispõe sobre a instituição do Sistema Nacional de Educação Tecnológica e dá outras providências. http://www.planalto.gov.br/ccivil_03/LEIS/L8948

Brasil. (2002). Decreto $n^{\circ} 30.766$ de 04 de março de 2002. Disciplina o sistema de cota para negros e pardos no acesso à universidade do estado do Rio de Janeiro e à universidade estadual do norte fluminense e dá eutras e http://alerjln1.alerj.rj.gov.br/decest.nsf/532ff819a4c39de50325681f0061559e/e3ad4849d25a8ee903256c44005f0bc6?OpenDocument

Brasil. (2004). Decreto $n^{\circ}$ 5.296, de 2 de dezembro de 2004. Regulamenta as Leis nos 10.048, de 8 de novembro de 2000, que dá prioridade de atendimento às pessoas que especifica, e 10.098, de 19 de dezembro de 2000, que estabelece normas gerais e critérios básicos para a promoção da acessibilidade das pessoas portadoras de deficiência ou com mobilidade reduzida, e dá outras providências. http://www.planalto.gov.br/ccivil_03/_ato2004-2006/2004/decreto/d5296.htm

Brasil. (2008). Lei n ${ }^{\circ} 11.892$, de 29 de dezembro de 2008. Institui a Rede Federal de Educação Profissional, Científica e Tecnológica, cria os Institutos Federais de Educação, Ciência e Tecnologia, e dá outras providências. http://www.planalto.gov.br/ccivil_03/_Ato2007-2010/2008/Lei/L11892.htm

Brasil. (2008b). Políticas de Inclusão da Rede Federal de Ensino Tecnológico e Profissional. Brasília, DF: MEC/SETEC.http://portal.mec.gov.br/setec/arquivos/pdf2/artigos_bases.pdf 
Brasil. (2010a). Lei ${ }^{\circ}$ 12.288, de 20 de julho de 2010. Institui o Estatuto da Igualdade Racial; altera as Leis nos 7.716, de 5 de janeiro de $1989,9.029$, de 13 de abril de 1995, 7.347, de 24 de julho de 1985, e 10.778, de 24 de novembro de 2003. http://www.planalto.gov.br/ccivil_03/_ato2007-2010/2010/lei/112288

Brasil. (2010b). Lei de Diretrizes e Bases para a Educação Nacional. Brasília - DF, Ministério da Educação, 2010. http://www2.camara.leg.br/legin/fed/lei/1960-1969/lei-4024-20-dezembro-1961-353722-norma-pl.htm>

Brasil. (2012a). Lei no 12.711 , de 29 de agosto de 2012. Dispõe sobre o ingresso nas universidades federais e nas instituições federais de ensino técnico de nível médio e dá outras providências. http://www.planalto.gov.br/ccivil_03/_ato2011-2014/2012/lei/112711.htm

Brasil. (2012b). Decreto $\mathrm{n}^{\circ} 7.824$, de 11 de outubro de 2012. Regulamenta a Lei $\mathrm{n}^{\circ} 12.711$, de 29 de agosto de 2012, que dispõe sobre o ingresso nas universidades federais e nas instituições federais de ensino técnico de nível médio. http://www.planalto.gov.br/ccivil_03/_ato20112014/2012/decreto/d7824.htm

Brasil. (2013a). Lei no 10.639, de 09 de janeiro de 2013. Altera a Lei no 9.394, de 20 de dezembro de 1996, que estabelece as diretrizes e bases da educação nacional, para incluir no currículo oficial da Rede de Ensino a obrigatoriedade da temática "História e Cultura Afro-Brasileira", e dá outras providências. http://www.planalto.gov.br/ccivil_03/leis/2003/110.639.htm

Brasil. (2013b). Lei n ${ }^{\circ} 12.799$, de 10 de abril de 2013. Dispõe sobre a isenção de pagamento de taxas para inscrição em processos seletivos de ingresso nos cursos das instituições federais de educação superior. http://www.planalto.gov.br/ccivil_03/_ato2011-2014/2013/lei/112799.htm

Brasil. (2014). Lei $\mathrm{n}^{\circ}$ 13.005, de 25 de junho de 2014. Aprova o Plano Nacional de Educação - PNE e dá outras providências. http://www.planalto.gov.br/ccivil_03/_ato2011-2014/2014/lei/113005.htm

Brasil. (2016). Lei $\mathrm{n}^{\circ}$ 13.409, de 28 de dezembro de 2016. Altera a Lei $\mathrm{n}^{\circ} 12.711$, de 29 de agosto de 2012, para dispor sobre a reserva de vagas para pessoas com deficiência nos cursos técnico de nível médio e superior das instituições federais de ensino. http://www.planalto.gov.br/ccivil_03/_ato20152018/2016/lei/113409.htm

Brasil. (2018). Censo da Educação Superior 2013,2017 e 2020. http://portal.mec.gov.br/docman/setembro-2018-pdf/97041-apresentac-a-o-censo-superior-ultimo/file

Camara, L. (2013). A educação na constituição federal de 1988 como um direito social. UNIJUÍ. DOI: https://doi.org/10.21527/2176-6622.2013.40.4-26 https://www.revistas.unijui.edu.br/index.php/revistadireitoemdebate/article/view/483

Castro, M. (2004). Políticas Públicas por Identidades e de Ações Afirmativas. Acessando gênero e raça, na classe, focalizando juventudes 1. Forum American Bar Association, v.2003, p.1-26.

Conselho Nacional de Educação. (2004). Resolução no 1, de 17 de junho de 2004. Institui Diretrizes Curriculares Nacionais para a Educação das Relações Étnico-Raciais e para o Ensino de História e Cultura Afro-Brasileira e Africana. Diário Oficial da União, Brasília (DF), 2004. http://portal.mec.gov.br/cne/arquivos/pdf/res012004.pdf

Ifsc. Instituto Federal de Educação de Santa Catarina. (2009a). Plano de Desenvolvimento Institucional. Florianópolis, http://intranet.ifsc.edu.br/images/file/Publicacoes/2011/PDI.pdf

Ifsc. Instituto Federal de Educação de Santa Catarina. (2009b). Plano de Inclusão do Instituto Federal de Santa Catarina (2009-2013). Florianópolis. http://intranet.ifsc.edu.br/images/file/Publicacoes/Plano\%20Inclusao\%202009-2013.pdf

Ifsc. Instituto Federal de Educação de Santa Catarina. (2013). Política de Comunicação do IFSC. https://www.ifsc.edu.br/documents/30701/523474/Politica_comunicacao_IFSC.pdf/4bf95874-d0f9-cc6b-1edd-85d404abd3e3

Ifsc. Instituto Federal de Educação de Santa Catarina. (2017a). Resolução Consup n ${ }^{\circ} 11$, de 24 de abril de 2017. Aprova o Regimento Interno do Câmpus Caçador. https://regimentos.ifsc.edu.br/files/2015/04/resolucao_consup_11_regimento_caador_def.pdf

Ifsc Instituto Federal de Educação de Santa Catarina. (2017b). Resolução Consup nº 41, de 19 de dezembro de 2017. Regulamenta, ad referendum, o Programa de Atendimento ao Estudante em Vulnerabilidade Social e suas ações no Instituto Federal de Santa Catarina. https://www.ifsc.edu.br/documents/175813/866662/Resolu\%C3\%A7\%C3\%A3o+PAEVS+atual/32ebea30-9650-c966-6c56-b3d4a3c5a2d8

Ifsc. Instituto Federal de Educação de Santa Catarina. (2018). Portal IFSC. Cotas. https://www.ifsc.edu.br/cotas\#: :text=O\%20IFSC\%20oferta\%20um\%20percentual,op\%C3\%A7\%C3\%A30\%20no\%20momento\%20da\%20inscri\%C3\%A7\%C3\%A3o

Ifsc. Instituto Federal de Educação de Santa Catarina (2019). http://www.ifsc.edu.br/menu-institucional/missao?id=152

Ifsc. Instituto Federal de Educação de Santa Catarina. (2020a). Resolução Consup n ${ }^{\circ} 07$ de 04/03/2020 - Aprova o Plano de Desenvolvimento Institucional do IFSC (2020-2024) https://www.ifsc.edu.br/pdi-2020-2024

Ifsc. Instituto Federal de Educação de Santa Catarina. (2020b). Instrução normativa no 16, de 29 de julho de 2020. Regulamenta procedimentos complementares à autodeclaração dos candidatos pretos, pardos e indígenas nos cursos técnicos de nível médio, de graduação e de pós-graduação do Instituto Federal de Santa Catarina. https://www.ifsc.edu.br/documents/177207/748318/IN_16_2020_Procedimentos+autodeclaracao+candidatos +ingresso+cursos+IFSC.pdf/28781377-c105-4b4e-b472-9c193794b8e8

Gil, A. (2010). Métodos e Técnicas de Pesquisa Social. (6a ed.), Atlas.

Kelbert, F. O. (2011). Reserva do possível e a efetividade dos direitos sociais no direito brasileiro. Livraria do Advogado Editora.

Klaus Junior, C. A., \& Hülse, L. (2020). English Immersion U.S.A. Program (EIP) - uma experiência educacional e sociocultural. Research, Society and Development, 9(8), e670986051. https://doi.org/10.33448/rsd-v9i8.6051 
Research, Society and Development, v. 10, n. 4, e15010414037, 2021

(CC BY 4.0) | ISSN 2525-3409 | DOI: http://dx.doi.org/10.33448/rsd-v10i4.14037

Krainski, L. B. (2008). Permanência e Sucesso no Ensino Superior: uma questão de direito. Eixo Temático: Políticas Públicas, Avaliação e Gestão da Educação. http://educere.bruc.com.br/arquivo/pdf2011/5678_2987.pdf

Kripka, R. M. L. \& Scheller, M. \& Bonotto, D. L. (2015) Pesquisa Documental na pesquisa qualitativa: conceitos e caracterização. Revista de Investigaciones UNAD. 14(2). https://core.ac.uk/download/pdf/322589335.pdf

Mereles, C. (2020). Cotas raciais no Brasil: o que são? Portal Politize. https://www.politize.com.br/cotas-raciais-no-brasil-o-que-sao

Nações Unidas. (2012). The future wewant. Conferência do Futuro. Rio de Janeiro. http://www.rio20.gov.br/documentos/documentos-da-conferencia/ofuturo-que-queremos/at_download/the-future-we-want.pdf

Peres, P. (2018). Como a Constituição de 1988 mudou a Educação. Revista Novaescola. Outubro de $2018 . \quad$ Disponível https://novaescola.org.br/conteudo/12660/como-a-constituicao-de-1988-mudou-a-educacao

Raposo, G. R. (2005). A educação na Constituição Federal de 1988. Jus Navigandi, Teresina, ano 10, n. 641, 10 abr. http://jus.com. br/revista/texto/6574

Silva, C. (2013). Ações afirmativas em educação: um debate para além das cotas. In: Silva, C. (Org.). Ações afirmativas em educação: experiências brasileiras. São Paulo: Summus. p. 17-38.

Silveira, M. (2019). Cotas sociais no Brasil. Politize. https://www.politize.com.br/cotas-sociais/

Silva, C. J. R. (Org.). (2009). Institutos Federais: Lei 11.892, de 29/12/2008- Comentários e Reflexões. Natal: Editora do IFRN.

Silva, D. N. (2021)."Constituição de 1988"; Brasil Escola https://brasilescola.uol.com.br/historiab/constituicao-1988.htm

Souza, C. C. (2015). O movimento indígena e a luta emancipatória. Dissertação (mestrado) - Universidade Federal de Santa Catarina, Centro de Filosofia e Ciências Humanas, Programa de Pós-Graduação em Sociologia Política, Florianópolis. https://repositorio.ufsc.br/handle/123456789/169350

Souza, M. F. (2019). A extinção da SECADI e o campo da Educação na conjuntura atual. Revista on-line. Ed. http://www.justificando.com/2019/01/17/extincao-secadi-campo-educacao-conjuntura-atual/

Stroisch, A. (2012). A permanência e o êxito dos alunos cotistas dos cursos superiores do Campus São José do Instituto Federal de Santa Catarina (20092010). Campinas, SP. http://repositorio.unicamp.br/jspui/handle/REPOSIP/250909? mode=full

Trevisol, J. V. \& Nierotka, R. L. (2015). "Lei das cotas" e as políticas de democratização do acesso ao ensino superior público brasileiro. Quaestilo - Revista de Estudos em Educação: 17(2). http://periodicos.uniso.br/ojs/index.php/quaestio/article/view/2406

Unicef. Declaração Universal dos Direitos da Criança. (2008). Adotada e proclamada pela Assembleia Geral das Nações Unidas (resolução 217 A III) em 10 de dezembro 1948.https://www.unicef.org/brazil/declaracao-universal-dos-direitos-humanos

Unifesp. Universidade Federal de São Paulo. (2014). Perguntas Frequentes. Coeficiente de Rendimento. https://www.unifesp.br/campus/sjc/perguntasfrequentes/413-coeficiente-de-rendimento.html

Warren, I. S. \& Passos, J. C. (2016) Ações Afirmativas Na Universidade - Abrindo novos caminhos. Organização. Editora UFSC. 